\title{
MEIO AMBIENTE DE TRABALHO E OS PRINCÍPIOS DO THE TRIPLE BOTTON LINE
}

\author{
WORK ENVIRONMENT AND THE PRINCIPLES OF THE TRIPLE BUTTON \\ LINE
}

Marcela andresa semeghini pereira ${ }^{1}$

\begin{abstract}
RESUMO: O objetivo desse texto foi tratar o direito ao meio ambiente ecologicamente equilibrado, em especial o meio ambiente de trabalho. Para isso apresentou-se o conceito sobre o assunto, suas natureza jurídica e a importância de se ter um meio ambiente de trabalho salubre, limpo, agradável, confortável e divertido, sendo confundido com práticas de lazer. Tratou-se da Constituição Federal, artigo 225, que preserva este direito, e do artigo 170, da mesma legislação, declarando que o trabalho humano e digno são princípios fundamentas para a manutenção da ordem econômica brasileira, concluindo que o meio ambiente de trabalho, que preserve a saúde mental e física do trabalhador e possibilite que o mesmo possua qualidade de vida, colaboram para a efetivação destes norteadores. Também, verificou-se que a legislação tende a acompanhar o desenvolvimento social, modernizando-se, sob pena de não considerar aspectos essenciais para que se cumpra o preconizado na Magna Carta. Concluiuse que, para a manutenção da ordem econômica e o trabalho digno, deve se considerar o Tripé da Sustentabilidade que destaca a interdependência de elementos econômicos, sociais e ambientais. Para o desenvolvimento da pesquisa, utilizou-se do método Aprendizado Centrado em Problemas, em que foram analisados os tópicos de aprendizado e são identificados a partir da apresentação de um problema real ou simulado. Frente ao problema, desenvolvem-se meios para solucioná-lo e, neste processo, identificam lacunas em seu conhecimento, buscando preenchê-las, com o auxílio de recursos instrucionais disponíveis.
\end{abstract}

PALAVRAS-CHAVE: Dignidade. Meio Ambiente de Trabalho. Sustentabilidade.

ABSTRACT: The aim of this paper was to treat the right to an ecologically balanced environment, especially the environment of work. For that presented the concept on the subject, their legal nature and the importance of having an environment of wholesome, clean, nice, comfortable and fun job being confused with leisure practices. It was the Federal Constitution, Article 225, which preserves this right, and Article 170 of the same law, stating that the human and decent work are key input to the maintenance of the Brazilian economic order principles, concluding that the working environment, to preserve the mental and physical health of the employee and allow that it has quality of life, facilitate realization of these guiding. Also, it was found that the law tends to follow social development, modernizing it, otherwise it will not take into account essential aspects that meets the recommendations in the Charter. It was concluded that, for the maintenance of the economic order and decent work should be considered the tripod of sustainability that highlights the interdependence of economic, social and environmental elements. For the development of research, we used a method Centered Learning Problems, where analyzes the topics of learning and are identified as presenting a real or simulated problem. Opposite problem, they

${ }^{1}$ Mestre em Direito pela Universidade de Marília/SP. MBA em Desenvolvimento Regional Sustentável pela Universidade Federal do Mato Grosso. 
develop ways to fix it and in the process, identify gaps in their knowledge, seeking to fill them with the help of instructional resources available.

KEYWORDS: Dignity. Work Environment. Sustainability.

\section{INTRODUÇÃO}

Considerando a preeminência de condições de trabalho humana e digna, partiu-se da premissa da essencialidade de um meio de ambiente de trabalho salubre, limpo, bonito, confortável e, se possível, divertido para que o trabalhador tenha maior qualidade de vida, e sua saúde física e mental seja preservada.

Em busca de respostas para a realização deste ambiente, procurou-se apresentar análise crítica a respeito da definição de meio ambiente em sentido amplo e meio ambiente de trabalho, divulgado o que preconiza a Constituição Federal de 1988, artigo 225, declarando que todos têm direito ao meio ambiente equilibrado, sendo este um bem de todo povo, essencial à qualidade de vida, sendo dever do Estado, da sociedade e de todo indivíduo a sua preservação, para continuidade da humanidade.

Enfatiza-se que a Constituição de 1988 foi à precursora na defesa do meio ambiente, prescrevendo um capítulo específico sobre este tema. Antes, o direito ambiental era meramente uma fundamentação teórica e, atualmente, é considerado um Direito Fundamental, essencial para a realização do princípio da dignidade da pessoa humana.

Embora sistematizado, constata-se que a legislação trabalhista trata o tema de forma retrógrada e limitada, como por exemplo, o que ocorre na Consolidação das Leis do Trabalho (1943), que disciplinou as agressões sofridas pelo trabalhador, proveniente de agentes físicos, químicos e biológicos.

Para sanar esta deficiência, o Senado propôs Projeto de Lei n 200, de 2014, o qual dispõe de alterações na Consolidação das Leis do Trabalho, onde se pretende estabelecer a garantia da incolumidade do trabalhador nos locais de trabalho, em especial dos menos abastados economicamente, unindo a necessidade econômica, social e ambiental defendidos pelo Tripé da Sustentabilidade, possuindo como finalidade a modernização da legislação brasileira. 
O texto magno, em seu artigo 170, informa que a proteção ao meio ambiente deve ser analisada como um dos axiomas basilares da ordem econômica brasileira. Fazendo-se mister a notoriedade do caráter econômico do Direito Ambiental, sendo essencial o seu equilíbrio ecológico para a garantia da qualidade de vida de todos.

Expuseram-se os principais aspectos jurídicos do tema meio ambiente do trabalho, sendo este um Direito Fundamental de terceira geração, de interesse transindividual e de natureza indivisível.

Além de sua sistematização na legislação nacional, o direito ambiental também está elencado nos normativos internacional. Promulgado nos princípios da Declaração de Estocolmo, de 1972 e validados no Brasil, pela Declaração do Rio, realizada na Conferência das Nações Unidas sobre o meio Ambiente e Desenvolvimento, Rio-92.

Comprovada a relevância do tema, verificou-se a pertinência em trata-lo à luz dos princípios do Tripé da Sustentabilidade (The Triple Botton Line), que conjuga a importância da harmonia de aspectos econômicos, sociais e ambientais para o alcance da dignidade da pessoa humana e manutenção da ordem econômica, inclusive o meio ambiente do trabalho ecologicamente equilibrado.

O método utilizado na presente pesquisa foi o Aprendizado Centrado em Problemas PBL (Problem Based Learning) neste verificam-se quais os tópicos de aprendizado são identificados a partir da apresentação de um problema real ou simulado. Frente ao problema, desenvolvem-se meios para solucioná-lo e, neste processo, identificam lacunas em seu conhecimento, buscando preenchê-las, com o auxílio de recursos instrucionais disponíveis.

Essa metodologia tem como características principais desenvolver as habilidades de gerenciar o aprendizado, de integrar conhecimentos e de identificar e explorar áreas novas, o que possibilitou a elaboração de trabalho inédito. Os problemas são primeiramente identificados e listados, e em seguida são formulados os objetivos, com base em tópicos considerados úteis para o esclarecimento e a resolução do problema.

Apropriou-se, para a evolução desta pesquisa, do método dedutivo, com consultas bibliográficas de doutrina, legislação e jurisprudência. Para enriquecer o trabalho, buscou-se o requisito multidisciplinariedade, contando também com contribuição das áreas das ciências econômicas, sociologia e ecologia. 


\section{DEFINIÇÃO DE MEIO AMBIENTE DO TRABALHO E ASPECTOS ECONÔMICOS E SOCIAIS}

A Constituição Federal de 1988 adotou dois aspectos para amparar o meio ambiente, que são: um imediato que é a qualidade do meio ambiente em todos os seus aspectos, e outro mediato que é a saúde, a segurança e o bem-estar do cidadão, expresso nos conceitos de vida em todas as suas formas (prescrito no artigo $3^{\circ}$, inciso I, da Lei $\mathrm{n}^{\circ} 6.938 / 91$ ) e em qualidade de vida.

O texto magno dispõe no artigo 225: “Todos tem direito ao meio ambiente ecologicamente equilibrado, bem de uso comum do povo e essencial à sadia qualidade de vida, impondo-se ao Poder Público e à coletividade o dever de defendê-lo e preserva-lo para as presentes e as futuras gerações.” Para melhor compreensão deste artigo, faz-se importante a análise crítica da definição de meio ambiente do trabalho.

A garantia constitucional do meio ambiente representa a valorização da humanização do trabalho, não se restringindo à preocupação com os aspectos econômicos que abarcam a atividade laboral, mas, sim, com a finalidade do trabalho como espaço de construção do bemestar, de identidade e de dignidade do homem que trabalha.

Privado de um espaço saudável, limpo e bonito, o homem, independente de sua condição, tem sua dignidade ferida, ainda que possua situação financeira abastada, visto que a qualidade de vida depende essencialmente de fatores sociais, econômicos e ambientais.

A definição de meio ambiente surgiu, legalmente, através da o artigo $3^{\circ}$, inciso I, da Lei $\mathrm{n}^{0}$ 6.938/81 - esta trouxe vários aspectos referentes ao meio ambiente em si, a sua definição legal e instituiu a Política Nacional do Meio Ambiente que prescreve que "meio ambiente é o conjunto de condições, leis, influências e interações de ordem física, química e biológica que permite, abriga e rege a vida em todas as suas formas”.

Nota-se que a Constituição Federal de 1988, não definiu o que é meio ambiente, mas é a primeira Constituição brasileira que dispõe de um capítulo atribuído exclusivamente ao meio ambiente, conforme se denota do Capítulo VI - Do Meio Ambiente (artigo 225), o qual está inserido no Título VIII - Da Ordem Social.

José Afonso da Silva (2000) expõe que o meio ambiente é uma miscelânea composta por elementos naturais, artificiais e culturais que propiciem ou contribuam para o desenvolvimento equilibrado da vida em todas as suas apresentações, sendo a preservação deste meio essencial para a continuidade da humanidade. 
Sobre o tema meio ambiente, Celso Antonio Pacheco Fiorillo (2000) chama atenção à importância em educar ambientalmente. De acordo com o autor, educar ambientalmente significa a redução dos custos ambientais, preservar de forma efetiva, fixar e ampliar a ideia de consciência ecológica, com a busca por tecnologias limpas, como por exemplo, a substituição dos combustíveis fósseis, engrandecer o princípio da participação, desenvolvendo-se o espírito da solidariedade, no sentido que o meio ambiente é único, pertencente a todos, sem divisões. O autor lembra que a manutenção e a melhoria do ambiente é dever de todos: sociedade, Estado e indivíduo.

Refletindo sobre o conceito de meio ambiente para o local onde o trabalho é praticado, tem-se que ele passa a abranger os métodos de trabalho, as ações para a realização das atividades, a forma como o empregador relaciona-se com o empregado e vice-versa, a forma como o empregado relaciona-se com os outros empregados, as medidas de seguranças, os procedimentos preventivos para que se proteja dos acidentes de trabalho, a adoção de novas ferramentas de trabalho que impeça o desgaste excessivo do trabalhador e outra prática.

O meio ambiente do trabalho faz parte do rol dos direitos fundamentais, ratificado pela Declaração do Meio Ambiente de Estocolmo, em 1972, adotado pela Conferência das Nações Unidas, elencando-se 26 princípios, que passaram a fazer parte da Declaração Universal dos Direitos do Homem. Cita-se o princípio 1 e o princípio 8, que diz:

Princípio 1- O Homem tem o direito fundamental a liberdade, à igualdade e ao desfrute de condições de vida adequada em um meio cuja qualidade lhe permite levar uma vida digna e gozar de bem-estar e tem a solene obrigação de proteger e melhorar esse meio para as gerações futuras.

Princípio 8- O desenvolvimento econômico ou social é indispensável para assegurar ao Homem um ambiente de vida e trabalho favorável e criar na Terra condições favoráveis para melhorar a qualidade de vida.

Nota-se que no princípio fala em assegurar ao Homem um ambiente de vida e de trabalho favorável. Favorável ao que e a quem? Certamente estes dizeres defendem a melhora nas condições de todos os homens, de todas as vidas, de todas as condições econômicas e sociais.

O homem está inserido no meio ambiente, assim como está inserido no meio ambiente do trabalho, sendo que este faz parte daquele. As realizações a serem alcançados através do trabalho, que no seu conjunto constituem-se em um dos grandes basilares da República Federativa do Brasil, na forma do seu artigo $1^{\circ}$, inciso IV, combinando com o artigo $7^{\circ}$, inciso XXII, que trata da redução dos riscos no trabalho, e, artigo 200, VIII, todos da Constituição, que traz literalmente, “colaborar na proteção do meio ambiente, nele compreendido o do 
trabalho”, tem-se que é obrigação da União, através do Sistema Único de Saúde, cuidar do ambiente de trabalho como um todo.

Para o autor José Afonso da Silva (2000, p. 5), o meio ambiente do trabalho corresponde "ao complexo de bens imóveis e móveis de uma empresa e de uma sociedade, objeto de direitos subjetivos privados, e de direitos invioláveis da saúde e da integridade física dos trabalhadores que o frequentam”.

Complementando o autor, Amauri Mascaro do Nascimento (2000) expressa o meio ambiente de trabalho como:

[...] o meio ambiente de trabalho é, exatamente, o complexo máquinatrabalho; as edificações, do estabelecimento, equipamentos de proteção individual, iluminação, conforto térmico, instalações elétricas, condições de salubridade ou insalubridade, de periculosidade ou não, meios de prevenção à fadiga, outras medidas de proteção ao trabalhador, jornadas de trabalho e horas extras, intervalos, descansos, férias, movimentação, armazenagem e manuseio de materiais que formam o conjunto de condições de trabalho etc.

A definição do doutrinador, Julio Cesar Sá da Rocha, é de que o meio ambiente do trabalho caracteriza-se como:

[...] a ambiência na qual se desenvolvem as atividades do trabalho humano. Diante das modificações por que passa o trabalho, o meio ambiente laboral não se restringe ao espaço interno da fábrica ou da empresa, mas se estende ao próprio local de moradia ou ao ambiente urbano. (2002, p. 30)

Resume-se, desta forma, o meio ambiente de trabalho como o espaço onde as pessoas desempenham suas atividades laborais, sejam remuneradas ou não, cujo equilíbrio baseia-se na salubridade/qualidade do meio e na ausência de elementos que prejudiquem de alguma forma a incolumidade físico-psíquica dos trabalhadores, independente da condição que exponha.

Diante dos conceitos citados, tem-se que o tema meio ambiente de trabalho é um ramo autônomo, sendo o seu objeto a proteção e valoração do homem no seu ambiente de trabalho contra as formas de degradação da sua sadia qualidade de vida. Considerando que, a grande maioria dos trabalhadores exerce atividades laborais durante 08 horas/dia, um terço do dia, confirma-se desta forma a importância de que este local seja limpo, bonito, agradável e confortável.

A abrangência de meio ambiente de trabalho não se limita apenas ao trabalhador que possui uma carteira profissional de trabalho que esteja assinada e registrada. Deve-se destacar que o meio ambiente de trabalho engloba todo trabalhador que exerce uma atividade, remunerada ou não, e porque todos estão amparados constitucionalmente de um ambiente de trabalho adequado e seguro, necessário à digna e sadia qualidade de vida. 
O texto da Constituição Federal, caput do artigo 170, apresenta o núcleo central da manutenção da ordem econômica no Brasil, que é a valorização do trabalho humano e digno. Por essa razão, considera-se que o ambiente de trabalho deve ser um local prazeroso e agradável ao trabalhador, podendo inclusive, quando adequado, confundir o trabalho com o lazer, afinal, porque o trabalho não pode ser divertido?

Em complemento ao estudado neste capítulo, tratar-se-á no próximo tema sobre os atributos jurídicos do meio ambiente do trabalho, citando a legislação internacional e nacional vigente que coadunam com a importância deste assunto.

\section{CARACTERÍSTICAS JURÍDICAS DO MEIO AMBIENTE DO TRABALHO}

O direito ao meio ambiente se encontra de forma expressa no texto da atual Constituição Federal, e sendo adjetivado como um Direito Fundamental, pela compreensão da harmonia dos seus artigos $1^{\circ}$, inciso III, e 225, caput, chega-se ao entendimento que a extensão do direito ao meio ambiente ecologicamente equilibrado é amplo e ilimitado, produzindo efeitos por diversas fases e de múltiplas consequências dificultando, muitas vezes, a efetividade deste direito.

O meio ambiente é qualificado como um direito fundamental de terceira geração, que são os direitos de solidariedade e fraternidade, como a paz no mundo, o desenvolvimento econômico dos países, a preservação do meio ambiente, do patrimônio comum da humanidade e da comunicação, os quais são imprescindíveis à condição humana e merecem a proteção do Estado e da sociedade em geral. Para conhecimento, os direitos de primeira geração são os direitos civis e políticos. Os direitos de segunda geração são os sociais, econômicos e culturais, os quais servem para dotar o ser humano das condições materiais necessárias ao exercício de uma vida digna.

Como verificado, Constituição Federal de 1988, pela primeira vez, destinou um capítulo específico ao meio ambiente. A questão ambiental, anteriormente comportava apenas uma fundamentação teórica e, hodiernamente, foi elevada ao status de norma de Direito Fundamental.

A preservação do meio ambiente é apreciada como um interesse difuso, tendo em vista que o meio ambiente é um bem jurídico de interesse de todos. O patrimônio ambiental, sendo de toda a humanidade, é qualificado como res omnium, ou seja, coisa de todos. 
O meio ambiente do trabalho equilibrado é parte integrante, e extremamente importante, do meio ambiente considerado na sua totalidade, é um direito difuso, ou seja, aquele cujo conceito legal é de interesse transindividual, de natureza indivisível, nos quais os titulares são pessoas indeterminadas e ligadas por circunstâncias de fato. Esta informação está em harmonia com o disposto no artigo 81, inciso I, do Código de Defesa do Consumidor, instituído pela Lei $n^{\circ}$ 8.078/90.

Nesse diapasão, apresenta-se a compreensão do autor, Celso Antonio Pacheco Fiorillo, que entende que (2004, p. 66) “a salvaguarda do homem trabalhador, enquanto ser vivo, das formas de degradação e poluição do meio ambiente onde exerce seu labuto, que é essencial à sua sadia qualidade de vida, é, sem dúvida, um direito difuso”.

O Código de Defesa do Consumidor aponta os direitos difusos, coletivos e homogêneos, em seu artigo 81, inciso I - interesses ou direitos difusos = entendem-se como os direitos transindividuais, de natureza indivisível, cujos titulares sejam pessoas indeterminadas e ligadas por circunstâncias de fato; inciso II - interesses ou direitos coletivos = entendem-se como os direitos transindividuais, de natureza indivisível de que seja titular o grupo, categoria ou classe de pessoas ligadas entre si ou com a parte contrária por uma relação jurídica base; e, por fim, o inciso III - interesses ou direitos homogêneos = entendidos como os de origem comum.

Na doutrina brasileira, verificam-se quatro aspectos do meio ambiente, sendo: o meio ambiente natural ou físico (solo, água, flora e fauna), o meio ambiente artificial (espaço urbano habitável - conjunto de edificações, espaços fechados, e equipamentos públicos), o meio ambiente cultural (patrimônio histórico, artístico, arqueológico, paisagístico e turístico) e o meio ambiente do trabalho.

Considerando o conceito uno de meio ambiente, consegue-se afirmar que o artigo 225 da Constituição de 1988 não limita totalmente, a tutela do meio ambiente a apenas um de seus aspectos, mas sim, tutela a dignidade e o bem-estar para a sadia qualidade de vida.

Em relação à natureza jurídica do ambiente do trabalho, leciona Fiorillo:

[...] a Constituição Federal de 1988 consagrou de forma nova e importante a existência de um bem que não possui características de bem público e, muito menos, privado, voltado à realidade do século XXI, das sociedades de massa, caracterizada por um crescimento desordenado e brutal avanço tecnológico. Diante desse quadro, a nossa Carta Magna estruturou uma composição para a tutela dos valores ambientais, reconhecendo-lhes características próprias, desvinculadas do instituto da posse e da propriedade, consagrando uma nova concepção ligada a direitos que muitas vezes transcendem o próprio critério das nações: os chamados direitos difusos. (2000, p. 10) 
Em complemento, contribui José Afonso da Silva:

A proteção ambiental, abrangendo a preservação da natureza em todos os seus elementos essenciais à vida humana e à manutenção do equilíbrio ecológico, visa tutelar a qualidade do meio ambiente em função da qualidade de vida, como uma forma de direito fundamental da pessoa humana [...] Esse novo direito fundamental foi reconhecido pela Declaração do meio Ambiente, adotada pela conferência das Nações Unidas, em Estocolmo, em junho de 1972, cujos vinte e seis princípios constituem prolongamento da Declaração Universal dos Direitos do Homem. (2000, p. 36)

O reconhecimento internacional do direito ao meio ambiente está expresso nos princípios da Declaração de Estocolmo, de 1972. Tais princípios, divulgados em Estocolmo, foram, ratificados, no Brasil, pela Declaração do Rio, realizada na Conferência das Nações Unidas sobre o meio Ambiente e Desenvolvimento, Rio-92.

Referente à legislação internacional, alude-se as inúmeras Convenção da Organização Internacional do Trabalho, devendo-se citar a $n^{0} 115$, que trata sobre proteção contra radiações ionizantes; a Convenção $\mathrm{n}^{\circ}$ 127, que menciona o peso máximo das cargas; a Convenção $\mathrm{n}^{0} 136$, que dispõe sobre proteção contra os riscos ocasionados pelo benzeno; a Convenção $n^{\circ}$ 85, que trata sobre prevenção e riscos profissionais provocados por substâncias cancerígenas no local de trabalho; a Convenção $n^{\circ} 148$, que dispõe sobre proteção contra os riscos provenientes da contaminação do ar, de ruído, e de vibrações no local de trabalho; a Convenção $\mathrm{n}^{\circ}$ 155, que aponta a segurança e saúde dos trabalhadores e meio ambiente de trabalho e o Protocolo de 2002 a respeito do assunto; a Convenção ${ }^{0}$ 161, que cita os serviços de saúde no trabalho; a Convenção $\mathrm{n}^{\circ}$ 162, que dispõe sobre a utilização do amianto com segurança; a Convenção $\mathrm{n}^{\circ}$ 170, que dispõe sobre a utilização de produtos químicos no trabalho, todas essas, sancionadas pelo Brasil, além de outras fontes, como as Portarias do Ministério do Trabalho, nas quais se enfatiza a Portaria $n^{0} 3.214 / 78$, composta de 30 Normas Regulamentadoras e a Portaria $n^{0}$ 598/2004, sobre instalações e serviços de eletricidade (BARROS, 2005, p. 1005).

Conjugando a legislação internacional e nacional, culmina-se no que preconiza a Constituição de 1988, que expressa como fundamento da ordem econômica (artigo 170) a valorização do trabalho humano. Complementa com o direito a dignidade humana, expressamente previsto no art. $1^{\circ}$, III, da citada, juntamente com as condições humanas de trabalho, possibilitando ao homem que trabalha possuir melhor qualidade de vida.

No entanto, apesar dos direitos declarados, Norberto Bobbio (2004, p. 25) afirma que o grande obstáculo dos direitos do homem, nos dias atuais, não é mais buscar seus 
fundamentos, mas, sim, protegê-los. Também considera que é indispensável à dedicação para criar condições visando à ampla realização dos direitos consagrados. Mas, para tanto, é preciso ter consciência “de que a realização dos direitos do homem é uma meta desejável”, e, para a efetivação de determinados direitos, exige-se muito mais que boa vontade dos governantes, como exemplo, a proteção dos direitos atinentes às relações de trabalho, que somente será possível mediante a transformação industrial em um país (2004p. 23), e conclui que a "efetivação de uma maior proteção dos direitos do homem está ligada ao desenvolvimento global da civilização humana”. (2004, p. 45)

De encontro com o exposto por Bobbio, verifica-se a essencialidade da existência de normas que assegurem direitos referentes às relações de trabalho, como a Constituição Federal que dispõe no artigo $7^{\circ}$, inciso XXII conjugado com o artigo 200, inciso VIII o qual garante ao trabalhador um meio ambiente do trabalho saudável e com melhor condição social e demonstra a grande importância do meio ambiente do trabalho na ordem econômica.

Art. $7^{\circ}$ São direitos dos trabalhadores urbanos e rurais, além de outros que visem à melhoria de sua condição social:

XXII - redução dos riscos inerentes ao trabalho, por meio de normas de saúde, higiene e segurança;

Art. 200. Ao sistema único de saúde compete, além de outras atribuições, nos termos da lei.

VIII - colaborar na proteção do meio ambiente, nele compreendido o do trabalho.

Complementando a reflexão, destaca-se a importância da vigência de normas que acompanhem os desafios da sociedade contemporânea, para que haja a efetivação dos direitos. Conflitando a esta relevante condição, a Consolidação das Leis do Trabalho, promulgada em 1943, não embebeu-se dos influxos da doutrina ambientalista que Estocolmo (1972) e Rio de Janeiro (1992) proporcionaram ao mundo. Esta mesma legislação também não premeditou a realidade trágica que o século XXI impôs aos ambientes de trabalho, nas áreas urbana e rural, podendo-se citar como exemplo as inúmeras ocorrências de trabalho análogo ao escravo. Portanto, é imprescindível que a legislação incorpore essa nova necessidade mundial nas dimensões conceitual, principiológica, preventiva e repressiva.

Os dizeres contidos na Consolidação das Leis do Trabalho, artigos 154 e seguintes, somente tratam das agressões à saúde do trabalhador no que diz respeito a agentes físicos, químicos e biológicos, deixando de lado as doenças provenientes do aspecto psicológico do meio ambiente do trabalho. 
Para corrigir a lacuna desta norma, o Senador Paulo Paim (2014) apresentou Projeto de Lei n 200, de 2014, o qual propõe modificações no artigo 161 da Consolidação das Leis do Trabalho, que objetivam contribuir para a modernização da legislação trabalhista. As alterações objetivam potencializar a proteção da incolumidade do trabalhador nos locais de trabalho, principalmente os mais humildes. $\mathrm{O}$ texto estende o poder de interditar e embargar a todo e qualquer auditor fiscal, se não houver razões explícitas para concentrá-lo nos superintendentes regionais; e permite que até mesmo o cidadão possa atuar em legítima defesa da integridade física de trabalhadores sob risco grave e eminente.

Este projeto de Lei (PAIM, Paulo, 2014) salienta que a matéria reclama tratamento legal mais minudente e sensível aos princípios retores do Direito Ambiental e, para isso, propõe a inclusão textual a "dimensão psicológica e os riscos psíquicos e ergonômicos” no tratamento legal do meio ambiente do trabalho, tanto em sua conceituação como em seu tratamento legal.

O Projeto n. 200(PAIM, Paulo, 2014) reconhece a figura da poluição do meio ambiente de trabalho, como também o seu agente indutor, nomeado como “poluidor laboral”, esclarecendo que essa poluição não se atém àqueles elementos que afetam desfavoravelmente a biota ou as condições estéticas e sanitárias do meio ambiente, como seriam os agentes químicos, físicos e biológicos em geral, de nocividade lenta e atual, comuns à noção de insalubridade. Também há poluição no ambiente de trabalho em contextos de periculosidade e de penosidade.

Esta proposta apresenta-se como um ganho social, econômico e ambiental para toda a população brasileira, por fim, destacam-se os argumentos conclusivos do Senador Paulo Paim, proponente do projeto:

[...] a aprovação deste Projeto de Lei para enfim sinalizar corretamente, já passados mais de vinte anos da Rio 92, o que não pode ser jamais esquecido: a dignidade irredutível do homem que labora e os riscos atuais a que se sujeita o trabalhador em seu local de trabalho. "Mas assim dizer não basta; há que agir. Cabe, dessarte, evocar uma vez mais a encíclica 'Centesimus Annus' para reconhecer, com a igreja, que a destruição das estruturas viciadas do habitat laboral, que ainda grassam no mundo contemporâneo e impedem a plena realização daqueles que vivem por elas oprimidos, bem como a sua substituição por formas de convivência mais autênticas e humanas, são tarefas que pressupõem coragem e paciência. Paciência, sobretudo àqueles que padecem a cada poro ou fôlego, as mazelas de um ambiente de trabalho poluído. E coragem aos operadores do Direito, notadamente juízes, advogados e membros do Ministério Público, para que 
não esmoreçam no bom combate.” (Guilherme Feliciano) Acresça-se agora: coragem, também, do legislador. (PAIM, Paulo, 2014)

De encontro com o Projeto de Lei do Senado, que abarca a necessidade de um meio ambiente de trabalho equilibrado, acrescenta-se a importância dos aspectos sociais e econômicos para que o trabalhador tenha uma vida e digna, cumprindo o preconizado o texto magno, artigo 170 caput que explicita à humanização que deve existir no ambiente de trabalho, divulgando que a ordem econômica deve estar fundamentada na valorização do trabalho humano, com o fim de assegurar a todos a existência digna, conforme os ditames da justiça social.

O tripé da sustentabilidade evidencia a conjugação de três elementos para o desenvolvimento de um país, e melhora na qualidade de vida de seus habitantes: social, econômico e ambiental.

\section{TRIPÉ DA SUSTENTABILIDADE (THE TRIPLE BOTTON LINE)}

Tripé da Sustentabilidade traz à baila que a sociedade, o Estado, os homens e as empresas não devem estar focados apenas no valor econômico que produzem, mas também nos valores ambientais e sociais que produzem ou destroem. Neste sentido, muitos falham em não reconhecer que o sucesso financeiro não é igual ao sucesso econômico, e que as suas escolhas econômicas são críticas para a realização de resultados social e ambiental, uma vez que, por natureza, o pilar econômico é intrinsecamente ligado aos pilares sociais e ambientais. (MONAGHAN, P.; SABATER, C.; WEISER, J, 2014)

Neste tripé estão contidos os aspectos econômicos, ambientais e sociais, que devem interagir, de forma holística, para satisfazer a formulação. Anteriormente, uma empresa era sustentável se tivesse economicamente saudável, ou seja, tivesse um bom patrimônio e um lucro sempre crescente, mesmo que houvesse dívidas.

Para um país, o conceito de tripé incluía um viés social. O desenvolvimento teria que incluir uma repartição da riqueza gerada pelo crescimento econômico, seja por meio de mais empregos criados, seja por mais serviços sociais para a população em geral. Esse critério, na maioria das vezes, é medido pelo Produto Interno Bruto (PIB) do país, o que para o novo conceito é uma medição limita. A perna ecológica do tripé trouxe, então, um problema e uma constatação. Se os empresários e os governantes não cuidassem do aspecto ambiental podiam ficar sem matéria-prima e talvez, sem consumidor, além causarem danos ambientais. 
A dimensão econômica da sustentabilidade refere-se aos impactos da organização sobre as circunstâncias econômicas de seus stakeholders e os sistemas econômicos nos níveis local e global. Assim, o desempenho econômico engloba todos os aspectos das interações econômicas da organização, incluindo as medidas tradicionais usadas na contabilidade financeira e os valores intangíveis que não aparecem sistematicamente nas citações financeiras.

Essencialmente, a ideia do tripé da sustentabilidade é que as empresas obtenham sua licença para operar não somente satisfazendo os seus acionistas através de lucros e dividendos (tripé econômico), mas pela satisfação simultânea de outros stakeholders da sociedade (empregados, comunidades, clientes e outros), através do melhor desempenho nos tripés ambiental e social. (SIGMA PROJECT, 2014)

Estas três dimensões também são reconhecidas pelo Instituto Ethos (INSTITUTO ETHOS, 2006), fundado em 1998 e referência no mercado brasileiro em responsabilidade social empresarial, que afirma que o adjetivo sustentável traz ao conceito de desenvolvimento um enorme desafio: conciliar eficiência econômica, equidade social e equilíbrio ecológico. Conforme Sachs (1993), precursor do termo eco desenvolvimento, acrescenta as dimensões espacial e a cultural. Segundo o autor (1993):

- Sustentabilidade social - busca o estabelecimento de um padrão de desenvolvimento que conduza à distribuição mais equitativa da renda, assegurando a melhoria dos direitos das grandes massas da população e a redução das atuais desigualdades sociais.

- Sustentabilidade econômica - é possível através de inversões públicas e privadas e da alocação e do manejo eficiente dos recursos naturais para redução dos custos sociais e ambientais.

- Sustentabilidade ecológica - entendida como o aumento ou a manutenção da capacidade de suporte do planeta, mediante intensificação do uso do potencial de recursos disponíveis, compatível com um nível mínimo de deterioração deste potencial; e a limitação do uso dos recursos não renováveis pela substituição por recursos renováveis e, ou, abundantes e inofensivos.

- Sustentabilidade espacial - busca uma configuração urbano-rural mais equilibrada, evitandose a concentração da população em áreas metropolitanas ou em assentamentos humanos em ecossistemas frágeis. 
- Sustentabilidade cultural - garantia da continuidade das tradições e continuidade da pluralidade dos povos.

Em termos estratégicos, esse modelo propõe que através de um bom gerenciamento do seu desempenho e dos seus impactos econômicos, ambientais e sociais, as empresas aumentam o seu valor a curto e longo prazo, bem como criam maiores oportunidades e reduzem riscos. Sendo evidente também, o ganho da sociedade e dos trabalhadores quando conjugados os aspectos econômicos, social e ambiental, influenciando diretamente na consequência de um ambiente de trabalho salubre e até mesmo divertido.

Os pontos a seguir representam o comportamento e as atitudes essenciais que são evidenciados nas empresas que buscam gerenciar e reportar de acordo com a linha do tripé da sustentabilidade (SUGGETT, D.; GOODSIR, B., 2002, p. 50):

- Aceitação de responsabilidade: o modelo é baseado na concepção de que as empresas são responsáveis não somente pela geração de valor para os acionistas ou proprietários, mas também para os stakeholders.

- Transparência: as empresas têm a obrigação, dentro dos limites comerciais, de ser transparentes em relação às suas atividades e aos seus impactos, além do desempenho financeiro.

- Operações e planejamento integrados: para a empresa contribuir para a prosperidade econômica (incluindo o retorno aos acionistas), a qualidade ambiental e o bem-estar social, é necessário que essas dimensões sejam refletidas no planejamento estratégico.

- Comprometimento com o engajamento dos stakeholders: a interação com os stakeholders internos e externos é um processo que informa os objetivos do negócio e é desenvolvido com base em rigorosa pesquisa e diálogo.

- Avaliação e relatório multidimensional: a análise sistemática e a verificação do desempenho econômico, ambiental e social, em conjunto com uma comunicação estruturada dos resultados, são os mecanismos mais frequentes para tornar concreto o que a empresa sustenta, como age e como assume os seus compromissos.

O conceito do tripé da sustentabilidade tornou-se amplamente conhecido entre as empresas e os pesquisadores, sendo uma ferramenta conceitual útil para interpretar às 
interações extra- empresariais e, especialmente, para ilustrar a importância de uma visão da sustentabilidade mais ampla, além de uma mera sustentabilidade econômica.

De encontro com este conceito deve-se destacar o tratamento do capital humano de uma empresa ou sociedade. Além de salários justos e estar adequado à legislação trabalhista, é preciso cuidar do bem estar dos seus funcionários, proporcionando um ambiente de trabalho agradável, saúde do trabalhador e da sua família. Sendo salutar a análise das consequências da prática das atividades econômicas nas comunidades, e como podem contribuir para a melhoria da qualidade de vida das pessoas.

O trabalho deve ser tratado com primazia, na forma do artigo 193 da Constituição Federal. Ou seja, na ordem econômica, o trabalho não pode ser simplificado e reduzido a expressões monetárias, fazendo do homem trabalhador uma mera engrenagem da produção, conjugado ao tripé da sustentabilidade - ganho econômico, social e ambiental - o ganho de qualidade de vida do trabalhador encerra o ciclo.

O capital natural de uma empresa ou sociedade é um elemento ambiental do tripé. Acredita-se que toda atividade econômica tem impacto ambiental negativo. Nesse aspecto, a empresa ou a sociedade deve pensar nas formas de diminuir esses impactos e repor ou compensar o que não é possível amenizar. Assim uma empresa que usa determinada matériaprima deve planejar formas de repor os recursos ou, se não é possível, diminuir o máximo possível o uso desse material, assim como saber medir a pegada de carbono do seu processo produtivo.

O autor Fritjof Capra (1997) traz importante contribuição ao tema ensinando que "sustentável" não se refere somente ao tipo de interação humana com o mundo que preserva ou conserva o meio ambiente para não comprometer os recursos naturais das gerações futuras, ou que visa unicamente à manutenção prolongada de entes ou processos econômicos, sociais, culturais, políticos, institucionais ou físico-territoriais, mas uma função complexa, que combina de uma maneira particular cinco variáveis de estado relacionadas às características acima. Capra exemplifica:

Quanto mais estudamos os principais problemas de nossa época, mais somos levados a perceber que eles não podem ser entendidos isoladamente. São problemas sistêmicos, o que significa que estão interligados e são interdependentes. Por exemplo, somente será possível estabilizar a população quando a pobreza for reduzida em âmbito mundial. A extinção de espécies animais e vegetais numa escala massiva continuará enquanto o Hemisfério Meridional estiver sob o fardo de enormes dívidas. A escassez dos recursos e a degradação do meio ambiente combina-se com populações em rápida 
expansão, o que leva ao colapso das comunidades locais e à violência étnica e tribal que se tornou a característica mais importante da era pós-guerra fria. (CAPRA, Fritjof, 1997, p. 23)

Para que a sociedade una-se novamente a teia da vida deve construir, nutrir e educar comunidades sustentáveis, nas quais se pode suprir vontades e necessidades sem impossibilitar as chances das gerações futuras. Para realizar essa tarefa, devem ser apreendidas valiosas lições extraídas do estudo de ecossistemas, que são comunidades sustentáveis de plantas, de animais e de microorganismos. Para compreender essas lições, é necessário compreender os princípios básicos da ecologia. Constata-se que este autor valida a necessidade do tripé, ou seja, a interdependência entre os fatores sociais, econômicos e ambientais.

Em complemento aos ensinamentos de Capra, considera-se também que os operadores do direito, cientes da fundamentalidade de uma análise sistêmica, elaborem leis condizentes com o momento da sociedade, visto que o Direito é efetivo não quando opera no plano do “dever ser” e sim no instante que se relaciona com a realidade da sociedade, ou seja, o plano do "ser".

Através desta reflexão, finaliza-se o presente trabalho convocando o Poder Público, a sociedade, empresas públicas e privadas, as famílias e todos os homens a assumirem a responsabilidade em buscar e manter um meio ambiente equilibrado, para o bem de todos e a preservação da humanidade.

O Tripé da Sustentabilidade demonstra que não só é possível, mas primordial, a efetivação do direito a um meio ambiente ecologicamente equilibrado conjugado ao desenvolvimento econômico e social, alcançando, desta forma, o princípio da dignidade da pessoa humana e a manutenção da ordem econômica, concordando-se que estes aspectos são importantes também para o desenvolvimento do país e a consequente melhora da qualidade de vida da população.

\section{CONCLUSÕES}

Constatou-se nesta pesquisa que para o homem possuir a "sadia qualidade de vida" preconizada pela Constituição Federal de 1988, em seu artigo 225, caput, é preciso que haja um meio ambiente equilibrado. O conceito de meio ambiente é unitário, englobando o meio 
ambiente do trabalho, de modo que não há como se almejar a melhora nas condições de vida se não existir espaço de trabalho salubre.

A Constituição Federal alvitra no artigo 170, que o núcleo central da manutenção da ordem econômica no Brasil, é a valorização do trabalho humano e digno, para isso, considerase que o ambiente de trabalho deve ser um local prazeroso e agradável ao trabalhador, podendo, inclusive, confundir o trabalho com o lazer. Desta forma, o trabalhador manterá a sua saúde física e, principalmente, mental.

Apurou-se a essencialidade da existência de normas que endossam direitos referentes às relações de trabalho, como a Constituição Federal que dispõe no artigo $7^{\circ}$, inciso XXII conjugado com o artigo 200, inciso VIII o qual afirma ao trabalhador um meio ambiente do trabalho saudável e com melhor condição social e demonstra a grande importância do local de trabalho na ordem econômica.

Acrescenta-se que desde 1943 ocorreram muitas modificações no mundo, sendo necessária a revisão da Consolidação das Leis do Trabalho. De encontro com esta constatação, o Senador Paulo Paim apresentou Projeto de Lei n 200, de 2014, este apresenta modificações no artigo 161 da Consolidação das Leis do Trabalho, que objetivam contribuir para a modernização da legislação trabalhista.

A aprovação desta lei otimizará a proteção da incolumidade do trabalhador nos locais de trabalho, principalmente os mais humildes. O texto amplia o poder de interditar e embargar a todo e qualquer auditor fiscal, se não houver razões explícitas para concentrá-lo nos superintendentes regionais; e permite que até mesmo o cidadão possa atuar em legítima defesa da integridade física de trabalhadores quando exposto a risco.

Concluiu-se que é função, não apenas do Poder Público, mas também da sociedade, empresas públicas e privadas, das famílias e cada uma das pessoas a responsabilidade em buscar e manter um meio ambiente equilibrado, para o bem de todos e a preservação da humanidade.

Por fim, a pesquisa possibilitou que fosse apurado que o meio ambiente de trabalho deve ser analisado juntamente com os aspectos econômicos e sociais, visto que o princípio da dignidade da pessoa humana é efetivado quando o Tripé da Sustentabilidade é posto em prática, culminando em práticas vantajosas para empregadores, empregados, Poder Público e sociedade. 


\section{BIBLIOGRAFIA}

BARROS, Alice Monteiro de. Curso de direito do trabalho. São Paulo: LTr, 2005.

BRASIL. Decreto-Lei $n^{\circ} 5.452$, de $1^{\circ}$ de maio de 1943. Aprova a Consolidação das Leis do Trabalho. Rio de Janeiro, 1 de maio de 1943, $122^{\circ}$ da Independência e 55 da República.

1988. . Constituição da República Federativa do Brasil de 1988. Brasília, 5 de outubro de

Lei $n^{\circ}$ 6.938, de 31 de agosto de 1981 Dispõe sobre a Política Nacional do Meio Ambiente, seus fins e mecanismos de formulação e aplicação, e dá outras providências.

CAPRA, Fritjof. A teia da vida: uma nova compreensão científica dos sistemas vivos. São Paulo: Cultrix, 1997.

FIORILLO, Celso Antonio Pacheco. Curso de Direito Ambiental Brasileiro. São Paulo: Saraiva, 2000. 2004.

Manual de direito ambiental e legislação aplicável. 5 ed., São Paulo, Ed. Saraiva,

INSTITUTO ETHOS. Critérios essenciais de responsabilidade social empresarial e seus mecanismos de indução no Brasil. São Paulo: Instituto Ethos, 2006.

MONAGHAN, P.; SABATER, C.; WEISER, J. Business and economic development: the impact of corporate responsibility standards and practices. Disponível em: $<$ www.accaglobal.com/pdfs/environment/newsletter/060303_bus_ed.pdf. 2003>. Acesso em: 16 jul. 2014.

NASCIMENTO, Amauri Mascaro do. A defesa processual do meio ambiente do trabalho. Revista LTr, 63/584, 2000.

PAIM, Paulo. Projeto de Lei do Senado n. 200 de 2014. Disponível em: http://www.senado.gov.br/atividade/materia/detalhes.asp?p_cod_mate=117967. Acesso em: 24 jul. 2014.

ROCHA, Júlio César de Sá da. A defesa processual do meio ambiente do trabalho: dano, prevenção e proteçãojurídica. São Paulo, Ed. LTr, 2002.

INSTITUTO ETHOS. Critérios essenciais de responsabilidade social empresarial e seus mecanismos de indução no Brasil. São Paulo: Instituto Ethos, 2006.

SIGMA PROJECT. The SIGMA Guidelines. Disponível em: <http://www.projectsigma.com>. Acesso em: 16 jul. 2014.

SILVA, José Afonso. Direito Ambiental Constitucional, 3ª ed. São Paulo: Malheiros, 2000.

SACHS, I. Estratégias de transição para o século XXI: desenvolvimento e meio ambiente. São Paulo: Livros Studio Nobel, 1993. 
SUGGETT, D.; GOODSIR, B. Triple bottom line measurement and reporting in Australia: making it tangible. Melbourne: DPA - Document Printing Australia, 2002. 